\title{
Inflation-Output Trade-off: Old Measures, New Determinants?
}

\author{
Georgios Magkonis* and Kalliopi-Maria Zekente ${ }^{\dagger}$
}

\begin{abstract}
This study analyses the determinants of the sacrifice ratio; i.e., the output cost of disinflation. The empirical literature so far has used several model specifications, indicating the degree of model uncertainty. Even for those factors where consensus on their significance has been reached, such as trade openness and central bank independence, considerable uncertainty still surrounds their estimated sign. Motivated by the above, we estimate the most important drivers of the sacrifice ratio based on Bayesian model averaging, for a panel data set of 42 countries. Our findings confirm part of the evidence reported in the prior empirical literature, while it sheds light on the importance of other factors.
\end{abstract}

Keywords: Sacrifice ratio, model uncertainty, model averaging

JEL Codes: E31, E32, F40

\footnotetext{
${ }^{*}$ Corresponding Author. Economics and Finance Subject Group, Portsmouth Business School, University of Portsmouth, (Email: georgios.magkonis@port.ac.uk).

${ }^{\dagger}$ Alpha Bank, Economic Research Division, 11 Sophocleous St., Athens, 10559, Greece.
} 


\section{Introduction}

During the 1980s, price stability became the primary concern for monetary policy in developed countries. The adoption of such a policy was a key element of what is now known as Great Moderation (Bernanke, 2004). At the same time, a new wave of academic research emerged, trying to explain on theoretical and empirical grounds the benefits of such a policy. One key aspect of the empirical literature was the short-run output losses that one economy may experience in the effort to reduce inflation. These effects were quantified by the ratio of cumulative output losses from a reduction of $1 \%$ of inflation. The magnitude of the sacrifice ratio, as well as, its determinants were an important piece of information for central banks. After the global financial crisis of 2008 and the recession that followed, many economies faced disinflation periods with associated output losses, while central banks of many developed economies significantly lowered their policy rates. New research appeared emphasizing the conditions of zero lower bound (Gust et al., 2017). Measuring the sacrifice ratio in such an environment became once again an important indication of the welfare effects of a recessionary period (Ascari and Ropele, 2012) ${ }^{1}$

Across the literature, three different approaches are typically followed to estimate the sacrifice ratio. The first approach is based on the estimation of a Phillips curve. The slope of the Phillips curve measures the response of output to changes in inflation and therefore, this estimate is used as a proxy of the inflation-output trade-off (Gordon et al., 1982, Gordon, 2013). The second method is the usage of structural VAR model (Cecchetti and Rich, 2001; Huh and Jang, 2007). In this setting, the sacrifice ratio is defined as the ratio of the cumulative response of output due to a monetary shock over the cumulative response of the inflation rate. The last method is based on the identification of actual disinflation episodes and the calculation of the associated losses in real output as a result. The exact calculation

\footnotetext{
${ }^{1}$ Sometimes the term "output-inflation trade-off" is used instead of the term "sacrifice ratio". However, the output-inflation trade-off is used to describe both the cost of output losses from a disinflation episode (sacrifice ratio) and the output gains from an increase in inflation (benefice ratio) (Jordan, 1997). Here, we use the terms "sacrifice ratio" and "output-inflation trade-off" interchangeably indicating only the former (i.e., the output cost of disinflation).
} 
procedure is discussed in Ball (1994). Due to its analytic simplicity, this method proves to be the most popular across the empirical literature.

The contribution of the present study is summarized as follows. Firstly, we estimate the sacrifice ratios for a panel of 42 countries. For each examined economy, we collect data for 13 variables that have been identified in the prior literature as potential drivers of the sacrifice ratio. These variables capture a range of macroeconomic, monetary and institutional features. Secondly, we identify the most significant drivers through a method that takes into account model uncertainty. Our results prove to be quite robust in a number of alternative assumptions and specifications. The remaining paper is structured as follows. Section 2 provides an overview of prior studies, while Section 3 describes the data collection process. The methodology is discussed in Section 4. Section 5 presents the main set of results, while Section 6 includes a series of robustness checks. Section 7 concludes.

\section{Literature Review and Motivation}

As outlined in the introductory section, the empirical research on the sacrifice ratio determinants reaches to mixed conclusions. ${ }^{2}$ This conflicting empirical evidence reflects the results' sensitivity to different subsets of the covariates used in each study. This leads to an omitted variable bias problem (see, for instance, Caporale and Caporale (2008), p.1544). Before discussing how we treat this problem, we provide a summary of the variables that have been used as driving forces of the sacrifice ratio. These factors addressed in the literature can be classified into the following broad categories.

The first group, which is typically treated as the benchmark set of regressors, is broadly related to features specific to the disinflation episode, i.e., its speed and duration, as well as, the peak and the change in inflation over the disinflation period. The literature has proposed conflicting views on the effect of the speed of disinflation. On the one hand, in the presence

\footnotetext{
${ }^{2}$ Here we focus only on papers that study the determinants of output-inflation trade-off. For a literature regarding the relation of the trade-off with specific macro variables, such as inflation and inflation variability see Bakas and Chortareas (2019).
} 
of wage and price rigidity, gradualism is shown to be less costly (Taylor, 1983) while, on the other hand, the choice of a quick disinflation process is associated with higher credibility gains and thus, with lower output losses (Sargent, 1983). The empirical findings in Ball (1994) corroborate the latter view; the speed of the disinflation episode is shown to be negatively associated with the sacrifice ratio. The argument in favour of a cold-turkey process rather than gradualism has also been corroborated by the results of subsequent studies including, among others, Jordan (1997), Caporale and Caporale (2008) and Gonçalves and Carvalho (2009). Conversely, the results by Mazumder (2014b) casts doubt on the findings in favour of a quicker disinflation process when measurements of the sacrifice ratio rely on core rather than on headline inflation. In addition to the speed of disinflation, the peak of inflation is also considered among the basic episode-specific determinants. While the earlier empirical findings of Ball (1994) do not corroborate the theoretical predictions of a negative association between the sacrifice ratio and the peak of inflation, Ball et al. (1988), Caporale and Caporale (2008), Roux and Hofstetter (2014) reach conclusions in support of the latter hypothesis.

The second broad class of factors focuses on the features of the monetary policy institutional framework and, in particular, the role of inflation targeting (IT), central bank independence (CBI) and central bank transparency. The findings by Gonçalves and Carvalho (2009), supporting the view that countries that have adopted an IT regime experienced less costly disinflations, have been challenged by Brito (2010) on the grounds of the sample employed and the impact of the Maastricht adjustment. More recently, Roux and Hofstetter (2014) show that IT results in lower sacrifice ratios only in the case of long disinflation episodes. As far as the central bank transparency is concerned, the evidence remains mixed. Although earlier empirical results support an inverse relationship between central bank transparency and the sacrifice ratio (Chortareas et al., 2003), in subsequent studies central bank transparency does not appear to be an important factor Gonçalves and Carvalho, 2009; Brito, 2010; Roux and Hofstetter, 2014).

In contrast to the presumption that $\mathrm{CBI}$, via enhanced credibility, is more to likely to 
be negatively associated with the sacrifice ratio, several studies have emphasized that higher CBI is associated with more costly disinflations (Jordan, 1997; Daniels et al., 2005). The empirical evidence by Caporale and Caporale (2008) suggest that CBI is not a significant determinant of the sacrifice ratio when controlling for the type of the government and other factors $3^{3}$ On the other hand, the results by Mazumder (2014a) support that a negative correlation between central bank independence and the sacrifice ratio appears to hold for non-OECD economies. An inverse relationship has been also corroborated by the empirical findings of Brumm and Krashevski (2003) as well as Diana and Sidiropoulos (2004) through the negative effect of central bank independence on inflation persistence.

A third group of potential determinants relates to the openness of the economies (e.g. trade openness and capital mobility), government indebtedness, labor market variables, the exchange rate regime, as well as, measures of the political stance. The results by Gonçalves and Carvalho (2009) and Roux and Hofstetter (2014) suggest that the public debt-to-GDP ratio does not appear to be an important determinant of the sacrifice ratio. The role of trade openness has received increased interest with a number of studies empirically examining the relationship between openness and inflation. Motivated by the hypothesis of an inverse association between openness and inflation by Romer (1993), earlier evidence by Temple (2002) indicate a negative, albeit weak, relationship between openness and the sacrifice ratio. Subsequent findings by Daniels et al. (2005) and Daniels and VanHoose (2009) suggest a positive relationship between openness and the sacrifice ratio when conditioning for CBI, while their interaction suggests that higher trade openness confines the effect of CBI on the sacrifice ratio. In addition to trade openness, Daniels and VanHoose (2009) obtain similar results when capital mobility is considered. Accounting for the interaction of capital mobility with CBI, greater capital mobility is associated with a higher sacrifice ratio. In contrast, the results by Bowdler (2009), taking also into account the exchange rate regime, indicate

\footnotetext{
${ }^{3}$ The findings by Caporale and Caporale (2008) have been criticized in the replication study by Katayama et al. (2011) supporting, in turn, a positive association when conditioning for the interaction of CBI and openness.
} 
a negative association between openness and the sacrifice ratio when a post-1980 sample of disinflation episodes is considered. A thorough discussion on the theoretical channels and the empirical evidence on the nexus between openness and the sacrifice ratio is provided by Daniels et al. (2015). Daniels and VanHoose (2013) provide evidence in favor of a positive association between the sacrifice ratio and the exchange rate pass through. The conclusions of Caporale and Caporale (2008) and Caporale (2011) suggest that right-wing governments experience less costly disinflations than left-wing on the basis of their stronger anti-inflation reputation. Recently, Daniels et al. (2019) provide evidence on the negative impact of the level and the change in inflation expectations on the sacrifice ratio.

A summary of the above discussion is given in Table 1. Apart from the different model specifications, the estimated effects differ significantly across studies. Figures 1a-4a plot the reported partial correlations against the corresponding standard errors for the most frequently used variables $(\Delta \pi$, peak, length and trade openness), while Figures $1 \mathrm{~b}-4 \mathrm{~b}$ depict the corresponding histograms $4^{4}$ From all graphs, it is evitable the degree of heterogeneity across the literature. The most pronounced heterogeneity across studies is observed for the peak and trade openness (Figures 3 and 4), where almost half of the estimates having an opposite sign. This is an indication of model uncertainty. As there is no a priori theoretical guidance regarding the significance or non-significance of certain factors, there is space for different model specification. This is the concept of open-endedness of theories developed by Brock and Durlauf (2001). The approach that allows to tackle this issue is a model averaging technique. In a contemporary paper, Katayama et al. (2019) find that the only important driver is the length of disinflation episodes. Our paper differentiates in the following ways. Firstly, we extend the examined countries from 19 economies to a group of 42 ones. Secondly, we search for the most robust drivers among a pool of 13 variables that covers a series of macroeconomic, monetary and institutional characteristics of the examined economies.

\footnotetext{
${ }^{4}$ We avoid showing the direct estimates or the t-statistics as these estimates are not comparable across studies. An easy way to make comparisons across studies is the usage of partial correlations. For more details, see Doucouliagos et al. (2012).
} 
Thirdly, we additionally use an averaging technique that takes into account not only model uncertainty but also any potential unobserved heterogeneity caused by the large sample of countries. Due to these three extensions, our results not only confirm the importance of the length, but also reveal the significance of other factors, mainly the role of capital openness.

Table 1 here

\section{Figures 1-4 here}

\section{Data}

As described in the previous section, our analysis is based on a sample of 42 economies. In this section, we analyse the specific definitions of the dependent variables. We collect data for real GDP and inflation rates for all countries with a full dataset over the period spanning 1974q12015q4. Then, we identify the disinflation episodes for each country. Following Ball (1994), the first step to identify a disinflation episode, based on quarterly data, is to define the peak and trough in trend inflation $\left(\pi^{T}\right)$, with the latter calculated as the nine-quarter moving average in actual inflation. The inflation peak, marking the beginning of the disinflation process, corresponds to the quarter in which trend inflation $\left(\pi_{t}^{T, p e a k}\right)$ is higher compared to the previous and subsequent four quarters $\left(\left(\pi_{t-4}^{T} \ldots \pi_{t-1}^{T}\right)<\pi_{t}^{T, \text { peak }}\right.$ and $\left(\pi_{t+4}^{T} \ldots \pi_{t+1}^{T}\right)<$ $\left.\pi_{t}^{T, p e a k}\right)$. By an analogy to the above, the trough signifies the end of the episode in which trend inflation $\left(\pi_{t}^{T, \text { trough }}\right)$ is lower against the previous and subsequent four quarters. For the calculation of output losses during the disinflation episode, one needs first to estimate output at its potential. According to the assumptions by Ball (1994), actual output reaches potential at the inflation peak and four quarters after the inflation trough, growing loglinearly in-between. Output losses are then calculated as the sum of the differences between actual and trend output. The sacrifice ratio of the disinflation episode is then measured as the total output losses over the difference in trend inflation. 
The number of disinflation episodes differs across economies; for those countries with available data after 1990, we identify one (for Russia and Latvia) and two disinflation episodes (for Estonia). On the contrary, for other economies we find more than four (Finland and Iceland, for instance). For the majority of countries, we are able to calculate three disinflation episodes and therefore, three sacrifice ratios. The total amount of episodes/observations is 153. Building on the seminal methodology proposed by Ball (1994), which proves to be the most popular across the related literature, Zhang (2005) and Hofstetter (2008) have also suggested two alternative methods to measure the sacrifice ratio. In particular, the approach proposed by Zhang (2005) takes into account the "long-lived" effects of a disinflation episode on output while the method by Hofstetter (2008) allows to capture both "long-lived" and lagged effects on output. In addition, Mazumder (2014b) calculates the sacrifice ratio based on all three variants, albeit relying on core rather than headline inflation. In the present study, we calculate the sacrifice ratios based on the standard Ball's method. The estimates and the countries included in the study are provided in the Table A1 in the Appendix. The data for the real GDP and inflation are drawn from the IMF-IFS and World Bank.

The starting point for the choice of the sacrifice ratios determinants hinges on the variables that have already been used in the literature. The first four indicators, which pertain to the specific characteristics of the disinflation process (peak, $\Delta \pi$, length and speed) are collected through the estimation method of Ball (1994) as explained above. The next step is the collection of macroeconomic variables. The most popular variables that have been frequently used in prior studies are measures of trade and capital openness. Both are proxies of how integrated the economies are to the rest of the world. In other words, they capture the globalisation effect. A proxy that measures a closely-related aspect is the concept of financial development (Mishkin, 2009). Even though no measure of financial development has been used in prior studies, we include a proxy of it. In this way, we investigate whether more advanced financial systems affect differently the inflation-output trade-off than less developed ones. An additional macro-variable, which has also been included in several prior 
studies, is the public debt-to-GDP ratio. Therefore, we also include it in our list of determinants. Finally, we use a proxy of employment protection to take into account the labour market characteristics. The choice for this variable was subject to data availability regarding our country sample.

The next category considers variables related to features of the monetary policy framework. In particular, we include a dummy that takes the value of 1 when a country is an inflation targeter (IT), a variable that measures the exchange rate flexibility and a proxy of CBI. On top of the above variables that have already been addressed in the sacrifice ratio literature, our study also examines whether the separation of monetary policy and banking supervision may have an impact on the sacrifice ratio. Although recent studies in monetary policy have emphasised the implications for monetary authorities from the separation of monetary policy from banking supervision (Ioannidou, 2005; Dincer and Eichengreen, 2012, Chortareas et al., 2016), this study is the first to the best of our knowledge to examine the effect of separating monetary policy and banking supervision on the sacrifice ratio. Roux and Hofstetter (2014), among others, have explicitly emphasized the role of credibility via both the speed of disinflation and the adoption of an inflation targeting regime and the associated gains in terms of output losses during a disinflation episode. Under a similar vein, a central bank being only in charge of the monetary policy function may be associated with enhanced credibility and thus, lower sacrifice ratios. Against this background and in order to be as inclusive as possible regarding the model specification, we include as an additional regressor a dummy that takes 0 when the central bank is involved in banking supervision, additional to its monetary policy task, and 1 when banking supervision is delegated to a separate institution (see Table A2). Table 2 presents the description of each variable along with the corresponding data source.

\section{Table 2 here}




\section{Methodology}

\subsection{Bayesian setup}

The key purpose is to identify the key drivers of the sacrifice ratio taking into account model uncertainty. This section discusses the methodological framework that we follow. The econometric model can be written as:

$$
s r_{i t}=c+x_{i t}^{j} \beta^{j}+e_{i t}, e_{i t} \sim N\left(0, \sigma^{2} I\right)
$$

where $s r$ is the sacrifice ratio for country $i$ at time $t$, the $x$ contains the explanatory variables and $c$ denotes the intercept. The uppercase $j$ indicates that the above equation is valid under model $M_{j}$. In our case, the usage of 13 regressors results to $2^{13}$ (more than 8 thousand) alternative models to choose from. This means that the model space consists of $M_{1}, \ldots, M_{j}$ models, where $j \in\left[1, \ldots, 2^{13}\right]$.

What BMA technique is doing is to assign a prior probability to each model, then to update these priors based on the data, and finally, to average across models. Therefore, the key feature is that the inference is not based on individual models, but on weighted averages. Based on Bayes rule, the posterior density for parameters $\beta$ is given by the following:

$$
p\left(\beta \mid s r, x, M_{j}\right) \propto p\left(s r \mid \beta, x, M_{j}\right) p\left(\beta \mid M_{j}\right)
$$

where $p\left(s r \mid \beta, x, M_{j}\right)$ is the likelihood function and $p\left(\beta \mid M_{j}\right)$ is the prior density. Treating $M_{j}$ as a parameter that its posterior has to be estimated using data plus a prior, Bayes rule can be written as:

$$
p\left(M_{j} \mid s r, x\right) \propto p\left(s r \mid M_{j}, x\right) p\left(M_{j}\right)
$$

The left-hand side term is the posterior model probability (PMP), while the right-hand 
side term is the marginal likelihood function, $p\left(s r \mid M_{j}, x\right)$, times the prior probability of model, $M_{j}$. Therefore, what is only needed for determining this posterior density is the calculation of the marginal likelihood. Combining equations (2) and (3), the marginal likelihood function can be expressed as:

$$
p\left(s r \mid M_{j}, x\right)=\int_{\beta} p\left(s r \mid \beta_{j}, x, M_{j}\right) p\left(\beta_{j} \mid M_{j}, x\right) d \beta_{j}
$$

Given the above, the posterior distribution of any $\beta$ coefficient is given by

$$
p(\beta \mid s r, x)=\sum_{j=1}^{2^{13}} p\left(\beta_{j} \mid s r, x, M_{j}\right) p\left(M_{j} \mid s r, x\right)
$$

where $p\left(\beta_{j} \mid s r, x, M_{j}\right)$ is the posterior distribution under model $M_{j}$ and $p\left(M_{j} \mid s r, x\right)$ is the posterior model probability. The above equation shows that the posterior model probabilities are used as weights. More precisely, the posterior density of $\beta_{j}$ for each model $M_{j}$ is weighted by the posterior model probability of each model $M_{j}$.

Depending on how frequently a regressor appears in the alternative $M_{j}$ models determines whether the regressor can be considered as robust determinant. This leads to the notion of posterior inclusion probability (PIP), which is just the sum of posterior model probabilities of all the models that include the specific regressor;

$$
P I P_{i}=\sum_{j=1} p\left(M_{j} \mid s r, x\right)
$$

with $i \in[1, K]$ indicating that each regressor has a specific PIP. The higher the PIP of a variable is, the greater its explanatory power. When the posterior inclusion probability of a variable is close to one, then almost all models of the model space include this variable. Here, we follow Kass and Raftery (1995) rule as a guide for the level of significance. Specifically, the effect of a variable is considered as weak, positive, strong, and decisive if its PIP lies between 0.5-0.75, 0.75-0.95, 0.95-0.99 and 0.99-1, respectively. 


\subsection{The choice of priors}

\subsubsection{Parameter priors}

As any Bayesian analysis, the BMA approach requires determining prior beliefs. More precisely, two kinds of beliefs are needed; prior for parameters and prior for the models. As far as the parameters are concerned, we have to specify the prior distributions for $c, \beta$ and $\sigma$. Given the lack of any prior knowledge, we follow the standard convention assuming non-informative priors for the intercept and the variance; that is, $p(c) \propto 1$ and $p(\sigma) \propto \sigma^{-1}$. Regarding the $\beta$ parameters which are the main interest of this study, we follow Zellner (1986) and assume that they are centered at zero and the variance is proportional to $\sigma^{2}\left(g\left(X_{i} X_{i}\right)^{-1}\right)$, where $g$ is the so-called Zellner's $g$ hyperparameter that indicates the level of our uncertainty. The larger the $g$ is, the larger the prior coefficient variance and, therefore, the higher the uncertainty. In summary, the coefficients' distribution depends on g:

$$
\beta_{i} \mid g \sim N\left(0, \sigma^{2}\left(g\left(X_{i} X_{i}\right)^{-1}\right)\right.
$$

In this study, we employ three different choices regarding $g$.

- Firstly, we employ the hyper-g prior as suggested by Liang et al. (2008). Specifically, $\frac{g}{1+g} \sim \operatorname{Beta}\left(1, \frac{a}{2}-1\right)$, where $\alpha \in(2,4]$ with a Beta distribution mean equal to $\frac{2}{\alpha}$. (In the Appendix (Table A3) we keep $\alpha$ at a fixed value).

- Secondly, we follow the 'empirical Bayes' $g$ approach proposed by George and Foster (2000) and Hansen and Yu (2001), where $g$ is determined by using information contained in the current dataset. This amounts to $g=\operatorname{argmax}_{g} p\left(s r \mid M_{j}, X, g\right)$.

- Finally, we set $g=N$, which leads to the most trivial case of unit information prior (UIP), where $N$ is the sample size. 


\subsubsection{Model priors}

The model prior setting that gives the probability of each model $M_{j}$ is written as:

$$
p\left(M_{j}\right)=\theta^{k_{j}}(1-\theta)^{K-k_{j}}
$$

where $K$ is the maximum number of regressors, $k_{j}$ is the number of regressors included in the model $M_{j}$ and $\theta$ is a hyperparameter that expresses the prior inclusion probability of each regressor. Based on this assumption, we discern between 2 different cases:

- Setting $\theta=\frac{1}{2}$ assigns equal probability to all models under consideration. The expected prior model size is equal to $\tilde{m}=\frac{K}{2}$ and, therefore, favours models of medium size. In our case, $\tilde{m}=\frac{13}{2}=6.5$. This leads to the uniform model prior, where each model has the same probability $p\left(M_{i}\right)=2^{-K}$. In Section 6.1 , we relax this assumption when we take into account fixed effects.

- We use an alternative model prior that is less restrictive as far as the model size is concerned, assuming a hyperprior beta-binomial with a prior model size of $K / 2^{13}$ from which the value of $\theta$ is drawn.

\subsection{MCMC sampler algorithm}

The total amount of the $K=13$ independent variables results to $2^{13}$ (more than 8 thousand) alternative models to choose from. Even though this number is not extremely high, we follow the standard and the most up-to-date practice of 'building from scratch' the posterior model distribution using a Markov Chain Monte Carlo (MCMC) sampler algorithm. At step 1, the sampler at model $M_{1}$ has a posterior model probability of a certain value, $p\left(M_{1} \mid, s r, x\right)$. At step 2 another model, $M_{2}$, is proposed to replace the previous one, $M_{1}$. The algorithm accepts the new model according to the following rate: 


$$
p_{1,2}=\min \left(1, \frac{p\left(M_{2} \mid s r, x\right)}{p\left(M_{1} \mid s r, x\right)}\right)
$$

If the model $M_{2}$ is rejected, the next model $M_{3}$ is proposed and compared with the $M_{1}$, using the same algorithm. With a very high number of iterations (here 200,000 with 100,000 used as burn-ins), the posterior model probability is empirically approached. In our case, due to the moderate amount of explanatory variables the analytical solution can be found. Therefore, we estimate the posterior model density as well as the posterior inclusion probabilities based analytically on all models as well as computationally as described above with a model space of 8,000 models. The results under both approaches are identical. We choose to present the method and the results based on the above computational scheme as this is the standard practice in Bayesian literature (see for instance, Arin et al. (2019) and Steel (2020)).

\section{$5 \quad$ Main Results}

Table 3 and 4 present the first set of results under different assumptions for model and parameter priors.$^{5}$ As explained earlier, we follow Kass and Raftery (1995) rule as a guide to the level of significance. Specifically, the effect of a variable is considered as weak, positive, strong, and decisive if its posterior inclusion probability (PIP) lies between 0.5-0.75, 0.750.95, 0.95-0.99 and 0.99-1, respectively. The most robust determinants of the sacrifice ratio are the length and the speed of disinflation episode as well as the central bank independence (CBI) and the capital openness.

The length of the disinflation episode proves to be one factor for which the majority of prior studies agrees on. Regardless of the various model specifications that have been employed, the estimated parameter is consistently found to be positive (although not always statistically significant) as Figure 2b shows. Precisely, $93 \%$ of the estimates are found to

\footnotetext{
${ }^{5}$ Additional results are presented in Table A3 in the Appendix.
} 
be positive. Our BMA exercise confirms this result indicating that a longer disinflation episode is associated with greater output losses and, thus, a higher sacrifice ratio (Daniels and VanHoose, 2013). Furthermore, the speed of a disinflation comes with a negative sign. This is in accordance with the majority of previous findings. A negative correlation gives supports to Ball (1994) argument in favour of cold turkey strategy; i.e., a quick disinflation process is accompanied with less output loss.

Central bank independence is the only aspect of the institutional monetary policy framework that has been so extensively included in previous studies. Jordan (1997) is the first to suggest a positive relationship between $\mathrm{CBI}$ and sacrifice ratio. A central bank that is more independent from the political regime tends to encounter higher sacrifice ratios. This relationship is also confirmed by Daniels et al. (2005). However, more recent studies have challenged this view. Caporale and Caporale (2008) conclude that there is no significant effect. Mazumder (2014a) finds that higher CBI from political pressures helps economies to lose less output during disinflations. According to his analysis, this result holds only for non-OECD countries. Our empirical outcome supports a negative relationship. This evidence validates the first theoretical studies (Walsh, 1995) that argue that more CBI tends to flatten the Phillips curve; i.e., reducing the sacrifice ratio.

The concept of capital openness has received more limited attention in the prior empirical literature. Daniels and VanHoose (2009) report both positive and negative effects based on model specification. Our evidence suggests that more open economies tend to experience higher sacrifice ratios. Daniels and VanHoose (2009) conclude that their empirical outcome is more in favour of a positive relationship, even though their theoretical framework predicts a reduced sacrifice ratio due to the globalisation effect. Our results confirm this positive link. This evidence is also related to the literature that examines the spill-over effects on real activity that comes from the emerging markets after 1980s (World Bank, 2016). This does not come as a surprise considering that part of our country sample consists of countries that experienced sudden changes in their capital account. The remaining variables do not 
seem to be robust drivers of sacrifice ratio. Other institutional and monetary aspects, such as IT, do not prove to be significant (Brito, 2010) $!^{6}$

Table 3 here

Table 4 here

\section{Robustness analysis and further evidence}

\subsection{Country heterogeneity}

The first robustness exercise is the inclusion of country heterogeneity. We employ the BMA estimator proposed by Moral-Benito (2012) and Moral-Benito and Roehn (2016). Assuming uniform model prior this estimator assigns equal probability to each model, that is $\theta=0.5$. Regarding the parameters, unit information prior is assumed. Since this extension works only for balanced panels, we have to adjust our sample and, specifically, the number of ratios per country to be included in our sample.7 The maximum number of observations is achieved when we include three ratios per country. The alternative options, of either selecting four episodes per country or dropping out countries with less than three episodes, reduce significantly our sample. Therefore, the optimal choice is to include three estimated ratios per country, which results in 102 observations in total. The results, as shown in Table 5, confirm our baseline findings; the length of disinflation, CBI and capital openness still remain robust drivers of the sacrifice ratio, with the same estimated sign. Moreover, when taking into account cross-country effects, trade openness is also found to be negative and highly significant in line with Daniels et al. (2015).

\section{Table 5 here}

\footnotetext{
${ }^{6}$ In the case of the unbalanced panel dataset, we do not include the proxy variable for the employment protection due to data availability. In the next section, where the number of countries is reduced, this variable is used.

${ }^{7}$ Both Moral-Benito (2012, p.573) and Moral-Benito and Roehn (2016, p.151) explicitly state that BMA with fixed effects can only be applied in balanced panels.
} 
As a further robustness check, we use different values of $\theta$ while we control for fixed effects. In this way, we test whether the results remain the same when we shift the model distribution to either smaller or larger sizes. The mean prior model size is given by $\mathrm{k} \theta=\mathrm{k} / 2$, with $\mathrm{k}$ being the number of regressors. Table 6 shows the PIPs under two different prior inclusion probabilities. Specifically, we test our benchmark results by choosing two different prior inclusion probabilities; by setting $\theta=0.34$ results in a smaller prior model size of $\mathrm{k} \theta=4.42$ while $\theta=0.69$ implies a larger model size of 8.97. Under both assumptions, our results remain qualitatively the same as in the benchmark specification for the role of central bank independence and capital openness. The length of the disinflation episode is not significant only in the case of the low prior inclusion probability $(\theta=0.34)$. Irrespective of the model size, trade openness is still found to be an important determinant of the sacrifice ratio. Table A4 in the Appendix summarises all the empirical specifications presented in the paper.

\section{Table 6 here}

\subsection{Removing outliers and subsample analysis}

As an additional robustness check, we remove from our initial dataset the disinflation episodes with extreme values of the sacrifice ratio or the initial inflation. The results are reported in Table 7 (without fixed effects) and Table 8 (with fixed effects). The length and the capital openness continue to be the most robust drivers in all specifications. In both cases (with and without fixed effects), CBI does not seem to be a significant factor anymore. On the contrary, when the outliers are removed Separation seems to become statistically significant with a positive sign.

Finally, we explore whether some results are driven by the fact that our sample consists of OECD and non-OECD countries. Following Masanjala and Papageorgiou (2008) we create a dummy for OECD countries. In order to do this split, we proceed without taking fixed effects as we want to use the total available sample (and not just the restricted balanced sample explained above) with the outliers being removed. The evidence shown in Table 9 
remains the same indicating that the results are not driven by the non-OECD countries. Like the previous evidence (Tables 7 and 8), the most robust drivers of the sacrifice ratio are the length and capital openness. CBI seems to be sensitive to the existence of outliers and becomes insignificant when they are removed. The opposite is true for the Separation where continues to an important driver of the sacrifice ration when extreme values are excluded.

\section{Table 7 here}

\section{Table 8 here}

\section{Table 9 here}

\section{Conclusions}

In the present study, we identify the most robust determinants of the sacrifice ratio taking into account model uncertainty. Focusing on a unbalanced panel of 42 countries, consisting of 153 disinflation episodes in total, we confirm the importance of factors for which the prior empirical literature has provided broadly conclusive evidence; a longer disinflation process tends to increase the associated output losses. Our study, however, reveals the importance of other variables whose both significance and their exact effect on the sacrifice ratio vary across prior studies. Capital openness is shown to be positively associated with the output cost of disinflation. Additionally, central bank independence is found to be negatively correlated with the sacrifice ratio. However, this relationship weakens when outliers are removed. The majority of our results prove to be robust to a series of checks including the assumptions of alternative priors and country heterogeneity. In addition, when cross-country fixed effects are taking into account, our evidence reveals the importance of trade openness in determining the sacrifice ratio. A potential extension to our BMA exercise is to explore the determinants of the sacrifice ratio when the latter is calculated based on the approach by Zhang (2005) and Hofstetter (2008). Future research could additionally consider the benefice 
ratio (as done by Jordan (1997)) and explore its driving forces. This would allow for a more thorough understanding as well as the evaluation of the factors behind the two stages of the economy i.e., between deflationary and inflationary episodes. Finally, a systematic research for determining the factors behind the heterogeneity of the reported estimates would shed new light on the output cost of the disinflation process. We leave these extensions for future research.

\section{Disclaimer}

The views and opinions expressed in this paper are those of the authors and do not necessarily reflect those of their respective institutions.

\section{Acknowledgements}

We would like to thank the Editor, Prof David VanHoose and two anonymous referees for their constructive comments and helpful suggestions. In addition, we would like to thank the participants of the 41st Annual Meeting of the Association of Southern European Economic Theorists for their comments and suggestions. Any remaining errors are the responsibility of the authors.

\section{References}

Arin, K. P., Braunfels, E., and Doppelhofer, G. (2019). Revisiting the growth effects of fiscal policy: A bayesian model averaging approach. Journal of Macroeconomics, 62:103158.

Ascari, G. and Ropele, T. (2012). Disinflation in a dsge perspective: Sacrifice ratio or welfare gain ratio? Journal of Economic Dynamics and Control, 36(2):169-182. 
Bakas, D. and Chortareas, G. (2019). Inflation dynamics and the output-inflation trade-off: International panel data evidence. Forthcoming in Economic Inquiry.

Ball, L. (1994). What determines the sacrifice ratio? In Monetary policy, pages 155-193. The University of Chicago Press.

Ball, L., Mankiw, N. G., Romer, D., Akerlof, G. A., Rose, A., Yellen, J., and Sims, C. A. (1988). The new keynesian economics and the output-inflation trade-off. Brookings Papers on Economic Activity, 1988(1):1-82.

Bernanke, B. (2004). The great moderation, in: E.f.koenig (ed.), the taylor rule and the transformation of monetary policy.

Bodea, C. and Hicks, R. (2015). Price stability and central bank independence: Discipline, credibility, and democratic institutions. International Organization, 69(1):35-61.

Bowdler, C. (2009). Openness, exchange rate regimes and the phillips curve. Journal of International Money and Finance, 28(1):148-160.

Bowdler, C. and Nunziata, L. (2010). Labor market structures and the sacrifice ratio. Journal of Macroeconomics, 32(3):816-826.

Brito, R. D. (2010). Inflation targeting does not matter: another look at oecd sacrifice ratios. Journal of Money, Credit and Banking, 42(8):1679-1688.

Brock, W. A. and Durlauf, S. N. (2001). What have we learned from a decade of empirical research on growth? growth empirics and reality. The World Bank Economic Review, 15(2):229-272.

Brumm, H. J. and Krashevski, R. S. (2003). The sacrifice ratio and central bank independence revisited. Open Economies Review, 14(2):157-168.

Caporale, B. and Caporale, T. (2008). Political regimes and the cost of disinflation. Journal of Money, Credit and Banking, 40(7):1541-1554. 
Cecchetti, S. G. and Rich, R. W. (2001). Structural estimates of the us sacrifice ratio. Journal of Business \& Economic Statistics, 19(4):416-427.

Chinn, M. D. and Ito, H. (2006). What matters for financial development? capital controls, institutions, and interactions. Journal of Development Economics, 81(1):163-192.

Chortareas, G., Logothetis, V., Magkonis, G., and Zekente, K. (2016). The effect of banking supervision on central bank preferences: Evidence from panel data. Economics Letters, $140(3): 11-13$.

Chortareas, G., Stasavage, D., and Sterne, G. (2003). Does monetary policy transparency reduce disinflation costs? The Manchester School, 71(5):521-540.

Copelovitch, M. S. and Singer, D. A. (2008). Financial regulation, monetary policy, and inflation in the industrialized world. The Journal of Politics, 70(3):663-680.

Daniels, J. P., Mazumder, S., and VanHoose, D. D. (2015). Implications of globalization for the output-inflation relationship: An assessment. Open Economies Review, 26(1):39-60.

Daniels, J. P., Mazumder, S., and VanHoose, D. D. (2019). Expected inflation and the sacrifice ratio. International Finance, 22:307-322.

Daniels, J. P., Nourzad, F., and VanHoose, D. D. (2005). Openness, central bank independence, and the sacrifice ratio. Journal of Money, Credit, and Banking, 37(2):371-379.

Daniels, J. P. and VanHoose, D. D. (2009). Trade openness, capital mobility, and the sacrifice ratio. Open Economies Review, 20(4):473-487.

Daniels, J. P. and VanHoose, D. D. (2013). Exchange-rate pass through, openness, and the sacrifice ratio. Journal of International Money and Finance, 36:131-150.

Di Noia, C. and Di Giorgio, G. (1999). Should banking supervision and monetary policy tasks be given to different agencies? International Finance, 2(3):361-378. 
Diana, G. and Sidiropoulos, M. (2004). Central bank independence, speed of disinflation and the sacrifice ratio. Open Economies Review, 15(4):385-402.

Dincer, N. N. and Eichengreen, B. (2012). The architecture and governance of financial supervision: Sources and implications. International Finance, 15(3):309-325.

Doucouliagos, H., Haman, J., and Stanley, T. (2012). Pay for performance and corporate governance reform. Industrial Relations: A Journal of Economy and Society, 51(3):670703.

George, E. and Foster, D. P. (2000). Calibration and empirical bayes variable selection. Biometrika, 87(4):731-747.

Gonçalves, C. E. S. and Carvalho, A. (2009). Inflation targeting matters: Evidence from oecd economies' sacrifice ratios. Journal of Money, Credit and Banking, 41(1):233-243.

Gordon, R. J. (2013). The phillips curve is alive and well: Inflation and the nairu during the slow recovery. Technical report, National Bureau of Economic Research.

Gordon, R. J., King, S. R., and Modigliani, F. (1982). The output cost of disinflation in traditional and vector autoregressive models. Brookings Papers on Economic Activity, 1982(1):205-244.

Gust, C., Herbst, E., López-Salido, D., and Smith, M. E. (2017). The empirical implications of the interest-rate lower bound. American Economic Review, 107(7):1971-2006.

Hammond, G. (2012). State of the art of inflation targeting. handbook 29. Center for Central Banking Studies, Bank of England.

Hansen, M. H. and Yu, B. (2001). Model selection and the principle of minimum description length. Journal of the American Statistical Association, 96(454):746-774.

Hofstetter, M. (2008). Disinflations in latin america and the caribbean: A free lunch? Journal of Macroeconomics, 30(1):327-345. 
Huh, H.-s. and Jang, I. (2007). Nonlinear phillips curve, sacrifice ratio, and the natural rate of unemployment. Economic Modelling, 24(5):797-813.

Ilzetzki, E., Reinhart, C., and Rogoff, K. (2008). Exchange rate arrangements entering the 21st century: which anchor will hold? Unpublished manuscript and data available online: http://personal. lse. ac. uk/ilzetzki/data. htm.

Ioannidou, V. P. (2005). Does monetary policy affect the central bank's role in bank supervision? Journal of Financial Intermediation, 14(1):58-85.

Jordan, T. J. (1997). Disinflation costs, accelerating inflation gains, and central bank independence. Weltwirtschaftliches Archiv, 133(1):1-21.

Kass, R. E. and Raftery, A. E. (1995). Bayes factors. Journal of the American Statistical Association, 90(430):773-795.

Katayama, H., Ponomareva, N., and Sharma, M. (2011). Central bank independence, political regimes, and the sacrifice ratio: A replication study of caporale and caporale (2008). Journal of Money, Credit and Banking, 43(5):1035-1042.

Katayama, H., Ponomareva, N., and Sharma, M. (2019). What determines the sacrifice ratio? a bayesian model averaging approach. Forthcoming in Oxford Bulletin of Economics and Statistics.

Liang, F., Paulo, R., Molina, G., Clyde, M. A., and Berger, J. O. (2008). Mixtures of g priors for bayesian variable selection. Journal of the American Statistical Association, 103(481):410-423.

Masanjala, W. H. and Papageorgiou, C. (2008). Rough and lonely road to prosperity: a reexamination of the sources of growth in africa using bayesian model averaging. Journal of Applied Econometrics, 23(5):671-682. 
Mazumder, S. (2014a). Determinants of the sacrifice ratio: Evidence from oecd and non-oecd countries. Economic Modelling, 40:117-135.

Mazumder, S. (2014b). The sacrifice ratio and core inflation. Journal of Macroeconomics, 40:400-421.

Mishkin, F. S. (2009). Globalization and financial development. Journal of Development Economics, 89(2):164-169.

Moral-Benito, E. (2012). Determinants of economic growth: a bayesian panel data approach. Review of Economics and Statistics, 94(2):566-579.

Moral-Benito, E. and Roehn, O. (2016). The impact of financial regulation on current account balances. European Economic Review, 81:148-166.

Romer, D. (1993). Openness and inflation: theory and evidence. The Quarterly Journal of Economics, 108(4):869-903.

Roux, N. D. and Hofstetter, M. (2014). Sacrifice ratios and inflation targeting: the role of credibility. International Finance, 17(3):381-401.

Sargent, T. (1983). Stopping moderate inflations: The methods of poincare and thatcher, in: Dornbusch, r. and m. simonsen (eds.), inflation, debt and indexation.

Steel, M. (2020). Model averaging and its use in economics. Forthcoming in Journal of Economic Literature.

Taylor, J. B. (1983). Union wage settlements during a disinflation. American Economic Review, 73(5):981-993.

Temple, J. (2002). Openness, inflation, and the phillips curve: a puzzle. Journal of Money, Credit and Banking, pages 450-468. 
Walsh, C. (1995). Output-inflation tradeoffs and central bank independence. FRBSF Economic Letter, (sep22).

Zellner, A. (1986). On assessing prior distributions and bayesian regression analysis with g-prior distributions. Bayesian Inference and Decision Techniques.

Zhang, L. H. (2005). Sacrifice ratios with long-lived effects. International Finance, 8(2):231262. 
Tables 
Table 1: Summary of existing literature

\begin{tabular}{|c|c|c|}
\hline Study & Main Explanatory variables used & Number of countries \\
\hline Ball (1994) & Peak, Speed, $\Delta \pi$, Length, Contract duration, Wage rigidity & 19 \\
\hline Temple 2002 & Peak, $\Delta \pi$, Length, Contract duration, Wage rigidity, TO & 19 \\
\hline Daniels et al. (2005) & Peak, $\Delta \pi$, Contract duration, Length, TO, CBI & 19 \\
\hline Caporale and Caporale 2008 & Peak, Speed, $\Delta \pi$, TO, CBI, Political regime & 18 \\
\hline Gonçalves and Carvalho (2009) & Peak, Speed, Debt, Transparency, IT & 30 \\
\hline Bowdler (2009) & TO, CBI, Length, EX*TO & 41 \\
\hline Daniels and VanHoose 2009) & Peak, $\Delta \pi$, Length, Contract duration, TO, CBI, CO & 16 \\
\hline Bowdler and Nunziata 2010 & Speed, Peak, TO, CBI, Wage rigitity Empl. protection & 17 \\
\hline Brito (2010) & Speed, Peak, Debt, Transparency, IT & 30 \\
\hline Katayama et al. 2011) & Speed, Peak, $\Delta \pi$, TO, CBI, Political regime & 18 \\
\hline Daniels and VanHoose (2013) & $\Delta \pi$, Peak, Length, CBI, Exchange rate pass-through, Union density & 20 \\
\hline Mazumder 2014a) & $\Delta \pi$, Length, CBI, IT, TO, Political regime, Debt, IT & 189 \\
\hline Mazumder 2014b) & Speed, $\Delta \pi$, Length, CBI, IT, TO & 22 \\
\hline Roux and Hofstetter (2014) & Speed, IT Debt, Transparency, Peak & 21 \\
\hline
\end{tabular}

Notes: This table presents a summary of the explanatory variables used by selected papers discussed in this study. 
Table 2: Variables used in the study

\begin{tabular}{|c|c|c|}
\hline Variable & Description & Source \\
\hline Peak & $\begin{array}{l}\text { Inflation at the start of the episode } \\
\text { the episode }\end{array}$ & $\begin{array}{l}\text { Own calculations based } \\
\text { on Ball }(1994)\end{array}$ \\
\hline$\Delta \pi$ & Change in trend inflation & $\begin{array}{l}\text { Own calculations based } \\
\text { on Ball (1994) }\end{array}$ \\
\hline Length & Length of the disinflation episode & $\begin{array}{l}\text { Own calculations based } \\
\text { on Ball }(1994)\end{array}$ \\
\hline Speed & $\Delta \pi /$ Length & $\begin{array}{l}\text { Own calculations based } \\
\text { on Ball }(1994)\end{array}$ \\
\hline Separation & $\begin{array}{l}\text { Dummy equals } 1 \text { when banking } \\
\text { supervision is delegated to a separate } \\
\text { institution other than the central bank }\end{array}$ & $\begin{array}{l}\text { Bank Regulation and Supervision Surveys, } \\
\text { World Bank; Copelovitch and Singer (2008); }\end{array}$ \\
\hline Inflation Targeting (IT) & $\begin{array}{l}\text { IT dummy equals } 1 \text { if at the } \\
\text { start of the disinflation episode } \\
\text { the IT regime was in force for at } \\
\text { at least } 2 \text { quarter as } \\
\text { in Gonçalves and Carvalho (2009) }\end{array}$ & $\begin{array}{l}\text { IT adoption dates based } \\
\text { on Hammond (2012) }\end{array}$ \\
\hline Central Bank Independence (CBI) & $\begin{array}{l}\text { Updated CWN index of de jure } \\
\text { cental bank independence }\end{array}$ & $\begin{array}{l}\text { Bodea and Hicks 2015 and } \\
\text { updated dataset }\end{array}$ \\
\hline Trade Openness (TO) & $\begin{array}{l}\text { sum of exports and imports of } \\
\text { goods and services measured as } \\
\text { as share of GDP }\end{array}$ & $\begin{array}{l}\text { World Development Indicators, } \\
\text { World Bank }\end{array}$ \\
\hline Debt & Government debt-to-GDP ratio & IMF Historical Public Debt Database \\
\hline Exchange rate regime (XR) & $\begin{array}{l}\text { Exchange rate classification } \\
\text { from soft to hard pegs }\end{array}$ & Dataset for Ilzetzki et al. (2008) \\
\hline Financial Development (FD) & $\begin{array}{l}\text { Domestic credit to private } \\
\text { sector as percentage of GDP }\end{array}$ & World Bank \\
\hline Capital Openness (CO) & $\begin{array}{l}\text { KAOPEN index measuring a } \\
\text { country's degree of capital } \\
\text { account openness }\end{array}$ & Chinn and Ito (2006) \\
\hline Employment protection & Index of employment protection & $\mathrm{OECD}$ \\
\hline
\end{tabular}

Notes: The table presents data sources for the variables included in the analysis. 
Table 3: Main Results I-Alternative model priors

\begin{tabular}{ccccc}
\hline Variable & $\mathrm{PIP}_{I}$ & $\mathrm{PIP}_{I I}$ & Effect on SR & Selected prior studies \\
\hline Peak & 0.277 & 0.436 & + & Te, DNV, DV1, DV2, Bo \\
$\Delta \pi$ & 0.276 & 0.435 & - & Ba, DNV, DV1, DV2, Ma1, Ma2 \\
Length & $0.811^{c}$ & $0.803^{c}$ & + & All studies listed in Table 1 \\
Speed & $0.828^{c}$ & $0.816^{c}$ & - & Ba, BN, RH, GC, CC, Br \\
Separation & 0.283 & 0.439 & + & Ma2 \\
IT & 0.402 & 0.530 & + & Bo, Ma1, CC \\
CBI & $0.857^{c}$ & $0.853^{c}$ & - & GC; Br \\
TO & 0.490 & 0.596 & + & Bo, BN, CC, DNV, DV1, Ma2 \\
Debt & 0.512 & 0.610 & + & DV1 \\
EXR & 0.281 & 0.438 & - & \\
FD & 0.357 & 0.494 & + & +
\end{tabular}

Notes: PIP stands for posterior inclusion probability, with subscripts I and II indicating uniform and beta-binomial model prior, respectively. The hyper-g prior is used as parameter prior. $a / b / c$ denotes decisive/strong/positive evidence of a regressor having an effect, respectively, according to Kass and Raftery (1995). +/- shows the estimated sign of the posterior mean of the corresponding coefficient. Prior studies are the studies that find similar evidence. These studies include: Ball (1994)-Ba, Temple (2002)-Te, Caporale and Caporale (2008)-CC, Bowdler (2009)-Bo, Daniels et al. (2005)-DNV, Daniels and VanHoose (2009)-DV1, Daniels and VanHoose (2013)-DV2, Gonçalves and Carvalho (2009)-GC, Bowdler and Nunziata (2010)-BN, Brito (2010)-Br, Daniels and VanHoose (2013)-DV, Roux and Hofstetter (2014)-RH, Mazumder (2014a)-Ma1, Mazumder (2014b)-Ma2. 
Table 4: Main Results II-Alternative parameters priors

\begin{tabular}{ccccc}
\hline Variable & PIP $_{I I I}$ & PIP $_{I V}$ & Effect on SR & Selected prior studies \\
\hline Peak & 0.295 & 0.295 & + & Te, DNV, DV1, DV2, Bo \\
$\Delta \pi$ & 0.294 & 0.294 & - & Ba, DNV, DV1, DV2, Ma1, Ma2 \\
Length & $0.829^{c}$ & $0.828^{c}$ & + & All studies listed in Table 1 \\
Speed & $0.845^{c}$ & $0.844^{c}$ & - & Ba, BN, RH, GC, CC, Br \\
Separation & 0.302 & 0.302 & + & Ma2 \\
IT & 0.422 & 0.422 & + & Bo, Ma1, CC \\
CBI & $0.869^{c}$ & $0.868^{c}$ & - & GC; Br \\
TO & 0.512 & 0.512 & + & Bo, BN, CC, DNV, DV1, Ma2 \\
Debt & 0.535 & 0.535 & + & DV1 \\
EXR & 0.299 & 0.299 & - & \\
FD & 0.376 & 0.376 & + & + \\
CO & $0.994^{a}$ & $0.993^{a}$ & + &
\end{tabular}

Notes: PIP stands for posterior inclusion probability with subscripts III and IV indicating 'empirical Bayes' $g$ and unit information parameter prior, respectively. The uniform is used as model prior. $a / b / c$ denotes decisive/strong/positive evidence of a regressor having an effect, respectively, according to Kass and Raftery (1995). + /- shows the estimated sign of the posterior mean of the corresponding coefficient. Prior studies are the studies that find similar evidence. These studies include: Ball (1994)-Ba, Temple (2002)-Te, Caporale and Caporale (2008)-CC, Bowdler (2009)-Bo, Daniels et al. (2005)-DNV, Daniels and VanHoose (2009)-DV1, Daniels and VanHoose (2013)-DV2, Gonçalves and Carvalho (2009)-GC, Bowdler and Nunziata (2010)-BN, |Brito (2010)-Br, Daniels and VanHoose (2013)-DV, Roux and Hofstetter (2014)-RH, Mazumder (2014a)-Ma1, Mazumder (2014b)-Ma2. 
Table 5: Robust 1-Results with country-specific fixed effects

\begin{tabular}{cccc}
\hline Variable & PIP & Effect on SR & Prior studies \\
\hline Peak & 0.679 & - & BN, RH \\
$\Delta \pi$ & 0.417 & + & CC \\
Length & $0.757^{c}$ & + & All studies listed in Table 1 \\
Speed & 0.269 & - & Ba, BN, RH, GC, CC \\
Separation & 0.337 & - & \\
IT & 0.695 & + & GC, RH, Ma2 \\
CBI & $0.800^{c}$ & - & Bo, Ma1, CC \\
TO & $0.939^{b}$ & - & Te; DV1 \\
Debt & 0.732 & + & GC; Br \\
EXR & 0.099 & - & Bo \\
FD & 0.133 & + & DV1 \\
CO & $0.992^{a}$ & + & BN \\
Empl.Prot. & 0.326 & + &
\end{tabular}

Notes: PIP stands for posterior inclusion probability. Unit information prior and uniform distribution are used as parameter and model priors, respectively. $a / b / c$ denotes decisive/strong/positive evidence of a regressor having an effect, respectively, according to Kass and Raftery (1995). +/- shows the estimated sign of the posterior mean of the corresponding coefficient. Prior studies are the studies that find similar evidence. These studies include: Ball (1994)-Ba, Temple (2002)-Te, Caporale and Caporale (2008)-CC, Bowdler (2009)-Bo, Daniels et al. (2005)-DNV, Daniels and VanHoose (2009)-DV1, Gonçalves and Carvalho (2009)-GC, Bowdler and Nunziata (2010)-BN, Brito (2010)-Br, Daniels and VanHoose (2013)-DV, Roux and Hofstetter (2014)-RH, Mazumder (2014a)-Ma1, Mazumder (2014b)-Ma2.

Table 6: Robust 2-Results with fixed effects \& alternative model priors

\begin{tabular}{ccccc}
\hline \multirow{2}{*}{ Variable } & \multicolumn{2}{c}{ PIPs under different prior inclusion probabilities } & & \\
\cline { 2 - 4 } & $\theta=0.34$ & $\theta=0.5$ & $\theta=0.69$ & Effect on SR \\
\hline Peak & 0.417 & 0.679 & $0.880^{c}$ & - \\
$\Delta \pi$ & 0.191 & 0.417 & 0.666 & + \\
Length & 0.595 & $0.757^{c}$ & $0.948^{c}$ & + \\
Speed & 0.218 & 0.269 & 0.462 & - \\
Separation & 0.222 & 0.337 & 0.564 & - \\
IT & 0.699 & 0.695 & 0.730 & + \\
CBI & $0.772^{c}$ & $0.800^{c}$ & $0.902^{c}$ & - \\
TO & $0.866^{c}$ & $0.939^{b}$ & $0.964^{b}$ & - \\
Debt & 0.535 & 0.732 & $0.863^{c}$ & + \\
EXR & 0.074 & 0.099 & 0.226 & - \\
FD & 0.057 & 0.133 & 0.208 & + \\
CO & $0.986^{b}$ & $0.992^{a}$ & $0.999^{a}$ & + \\
Empl.Prot. & 0.104 & 0.326 & 0.404 & + \\
\hline
\end{tabular}

Notes: PIPs stand for posterior inclusion probabilities. $\theta$ is the prior inclusion probability for each regressor. $\theta=0.5$ refers to the uniform model priors considered in the base line case presented in Table 5 . The mean prior model size is given by $\mathrm{k} \theta$ where $\mathrm{k}$ is the number of regressors. In our setting, the mean prior model size ranges from $4.42(\theta=0.34)$ to $8.97(\theta=0.69) . a / b / c$ denotes decisive/strong/positive evidence of a regressor having an effect, respectively, according to Kass and Raftery (1995). 
Table 7: Robust 3a-Excluding Outliers

\begin{tabular}{cccccc}
\hline Variable & $\mathrm{PIP}_{I}$ & $\mathrm{PIP}_{I I}$ & $\mathrm{PIP}_{I I I}$ & $\mathrm{PIP}_{I V}$ & Effect on SR \\
\hline Peak & 0.266 & 0.418 & 0.284 & 0.284 & + \\
$\Delta \pi$ & 0.278 & 0.428 & 0.296 & 0.296 & - \\
Length & $0.961^{b}$ & $0.965^{b}$ & $0.962^{b}$ & $0.963^{b}$ & + \\
Speed & 0.280 & 0.431 & 0.296 & 0.295 & + \\
Separation & $0.774^{c}$ & $0.802^{c}$ & $0.789^{c}$ & $0.789^{c}$ & + \\
IT & 0.656 & 0.721 & 0.674 & 0.674 & + \\
CBI & 0.462 & 0.581 & 0.484 & 0.484 & - \\
TO & 0.335 & 0.484 & 0.356 & 0.356 & + \\
Debt & 0.239 & 0.393 & 0.256 & 0.256 & + \\
EXR & 0.625 & 0.689 & 0.644 & 0.643 & + \\
FD & 0.430 & 0.547 & 0.447 & 0.643 & + \\
CO & $0.978^{b}$ & $0.982^{b}$ & $0.979^{b}$ & $0.979^{b}$ & + \\
\hline
\end{tabular}

Notes: PIP stands for posterior inclusion probability. The subscripts I, II, III and IV are showing the combinations of parameter and model priors as defined in Tables 3 and $4 . a / b / c$ denotes decisive/strong/positive evidence of a regressor having an effect, respectively, according to Kass and Raftery (1995). + /- shows the estimated sign of the posterior mean of the corresponding coefficient.

Table 8: Robust 3b-Results with fixed effects excluding outliers

\begin{tabular}{ccccc}
\hline \multirow{2}{*}{ Variable } & \multicolumn{2}{c}{ PIPs under different prior inclusion probabilities } & & \\
\cline { 2 - 4 } & $\theta=0.34$ & $\theta=0.5$ & $\theta=0.69$ & Effect on SR \\
\hline Peak & 0.364 & 0.632 & 0.697 & - \\
$\Delta \pi$ & 0.2678 & 0.365 & 0.416 & + \\
Length & $0.701^{c}$ & $0.748^{c}$ & $0.968^{c}$ & + \\
Speed & 0.368 & 0.412 & 0.459 & - \\
Separation & $0.751^{c}$ & $0.849^{c}$ & $0.899^{c}$ & + \\
IT & 0.452 & 0.541 & 0.569 & + \\
CBI & 0.421 & 0.489 & 0.512 & - \\
TO & $0.769^{c}$ & $0.798^{c}$ & $0.801^{c}$ & - \\
Debt & 0.336 & 0.487 & 0.541 & + \\
EXR & 0.179 & 0.299 & 0.379 & - \\
FD & 0.118 & 0.268 & 0.297 & + \\
CO & $0.957^{b}$ & $0.993^{a}$ & $0.999^{a}$ & + \\
Empl.Prot. & 0.0147 & 0.169 & 0.172 & + \\
\hline
\end{tabular}

Notes: PIPs stand for posterior inclusion probabilities. $\theta$ is the prior inclusion probability for each regressor. $\theta=0.5$ refers to the uniform model priors considered in the base line case presented in Table 5 . The mean prior model size is given by $\mathrm{k} \theta$ where $\mathrm{k}$ is the number of regressors. In our setting, the mean prior model size ranges from $4.42(\theta=0.34)$ to $8.97(\theta=0.69) . a / b / c$ denotes decisive/strong/positive evidence of a regressor having an effect, respectively, according to Kass and Raftery (1995). 
Table 9: Robust 4-OECD dummy

\begin{tabular}{cccccc}
\hline Variable & $\mathrm{PIP}_{I}$ & $\mathrm{PIP}_{I I}$ & $\mathrm{PIP}_{I I I}$ & $\mathrm{PIP}_{I V}$ & Effect on SR \\
\hline Peak & 0.217 & 0.469 & 0.318 & 0.387 & + \\
$\Delta \pi$ & 0.214 & 0.447 & 0.348 & 0.319 & - \\
Length & $0.997^{b}$ & $0.975^{b}$ & $0.974^{b}$ & $0.978^{b}$ & + \\
Speed & 0.216 & 0.411 & 0.397 & 0.487 & + \\
Separation & $0.757^{c}$ & $0.752^{c}$ & 0.709 & $0.774^{c}$ & + \\
IT & 0.668 & 0.703 & 0.621 & 0.637 & + \\
CBI & 0.635 & 0.648 & 0.614 & 0.601 & - \\
TO & 0.368 & 0.465 & 0.478 & 0.436 & + \\
Debt & 0.368 & 0.412 & 0.368 & 0.367 & + \\
EXR & 0.614 & 0.625 & 0.636 & 0.658 & + \\
FD & 0.597 & 0.556 & 0.457 & 0.487 & + \\
CO & $0.971^{b}$ & $0.975^{b}$ & $0.968^{b}$ & $0.981^{b}$ & + \\
OECD & 0.247 & 0.299 & 0.258 & 0.279 & + \\
\hline
\end{tabular}

Notes: PIP stands for posterior inclusion probability. OECD stands for a dummy that takes 1 for OECD economies and 0 otherwise. The subscripts I, II, III and IV are showing the combinations of parameter and model priors as defined in Tables 3 and $4 . a / b / c$ denotes decisive/strong/positive evidence of a regressor having an effect, respectively, according to Kass and Raftery (1995). +/- shows the estimated sign of the posterior mean of the corresponding coefficient. 


\section{Figures}

Figure 1: Partial correlations across studies for $\Delta \pi$
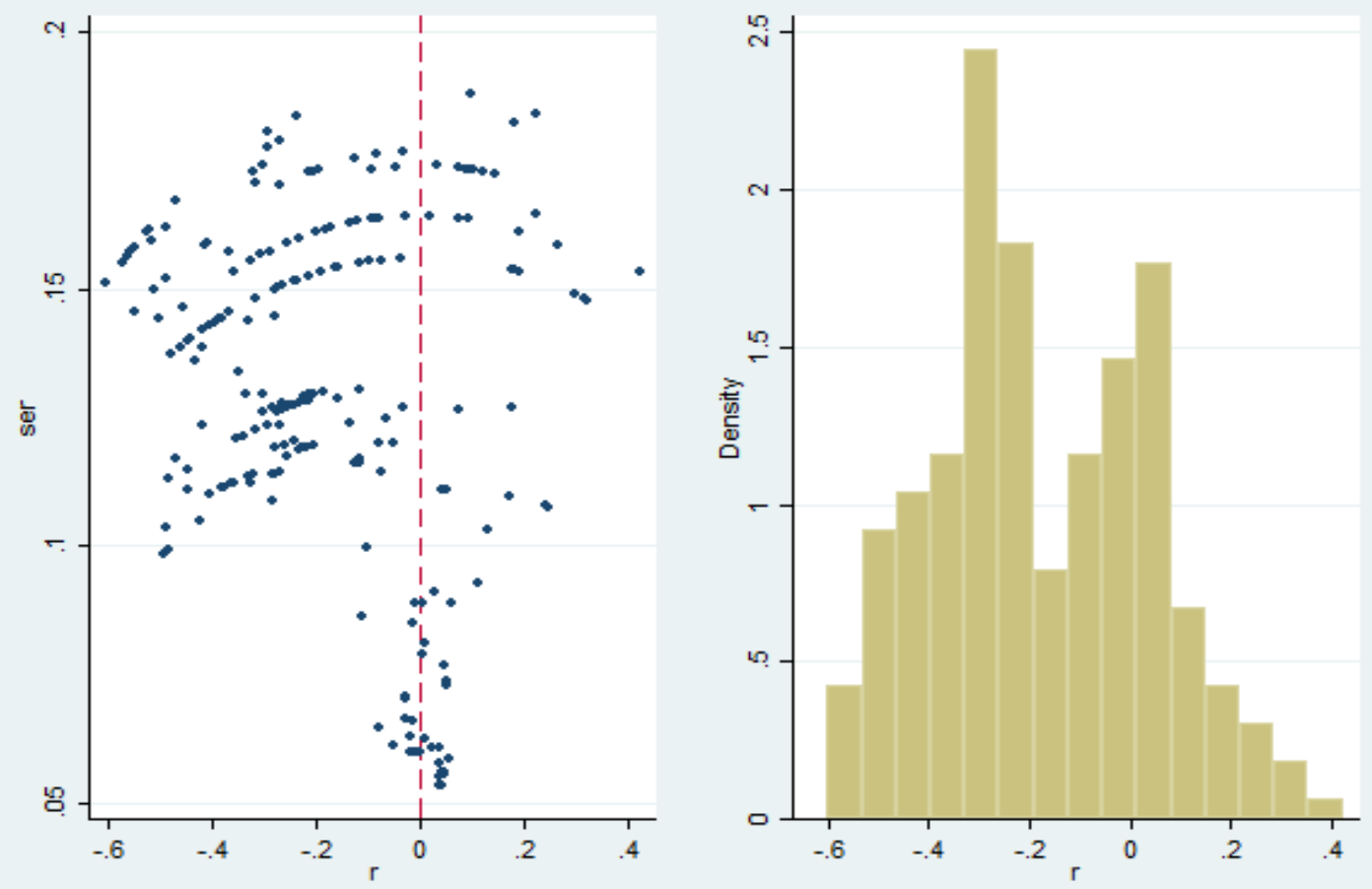

Notes: Figure (a) depicts the scatter plot of the partial correlations, r, and the corresponding standard errors, ser, for the reported estimates for $\Delta \pi$. Figure (b) shows the corresponding histogram of the reported t-statistics. 
Figure 2: Partial correlations across studies for Length

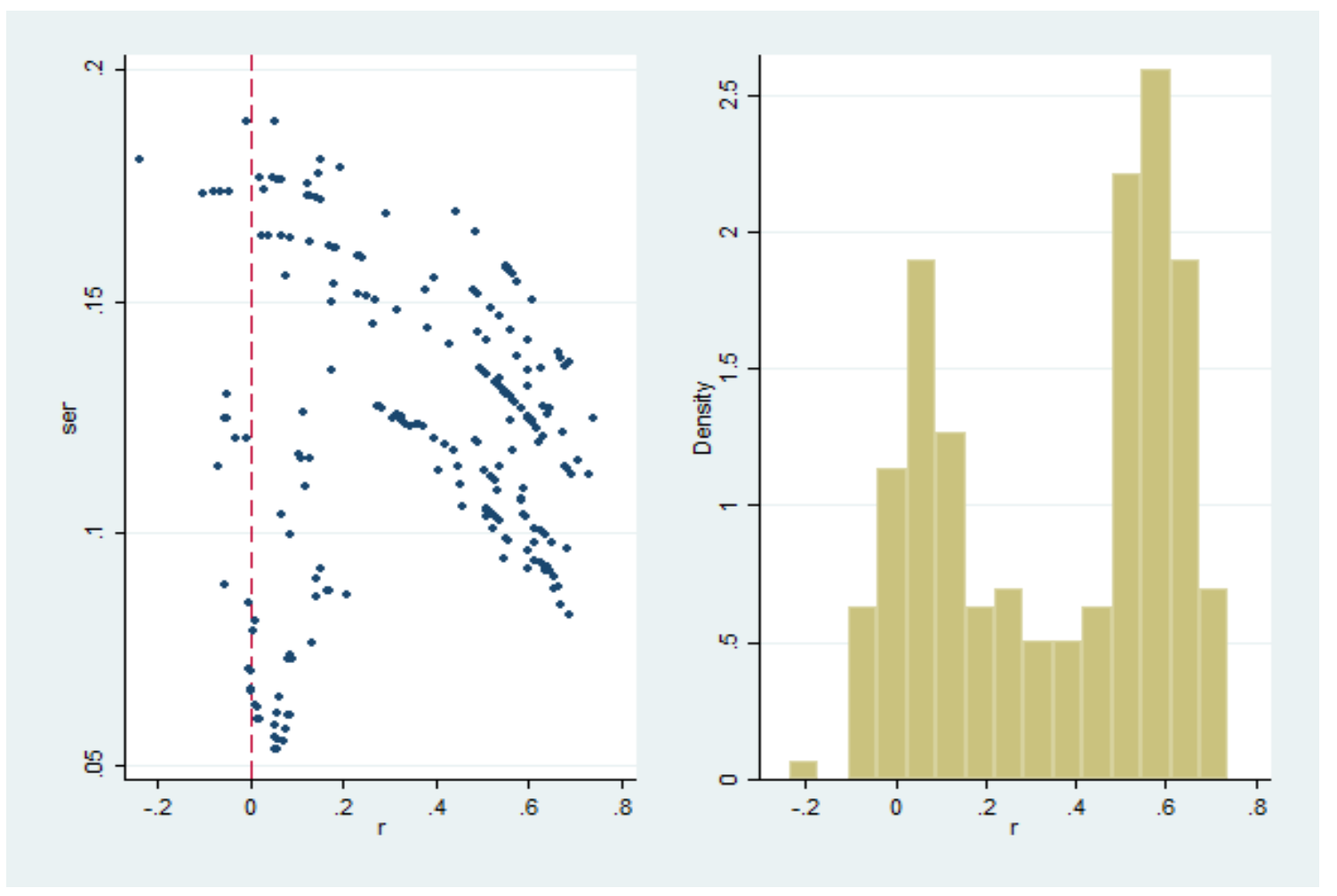

Notes: Figure (a) depicts the scatter plot of the partial correlations, r, and the corresponding standard errors, ser, for Length. Figure (b) shows the corresponding histogram of the reported t-statistics. 
Figure 3: Partial correlations across studies for Peak

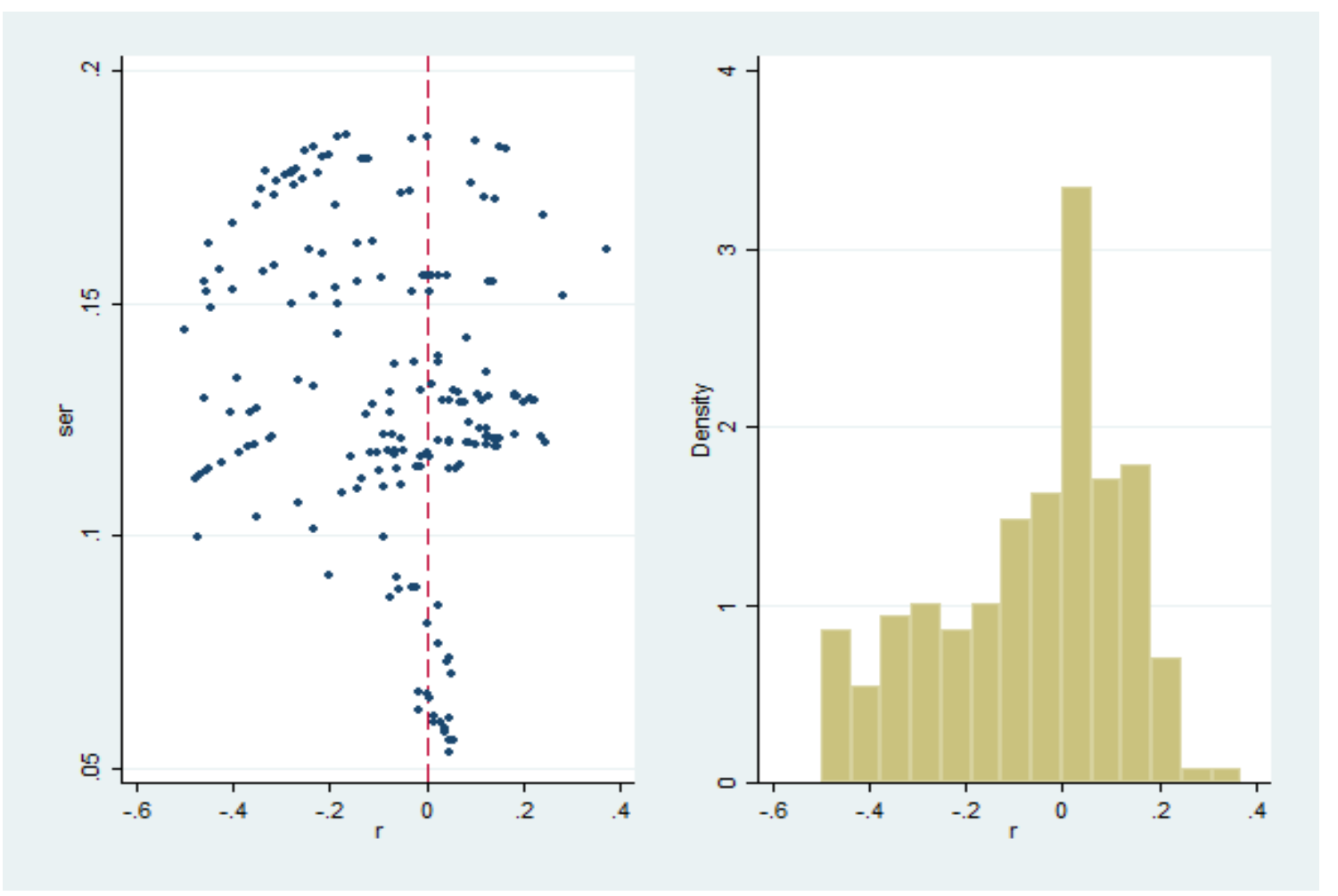

Notes: Figure (a) depicts the scatter plot of the partial correlations, r, and the corresponding standard errors, ser, Peak. Figure (b) shows the corresponding histogram of the reported t-statistics. 
Figure 4: Partial correlations across studies for Trade Openness

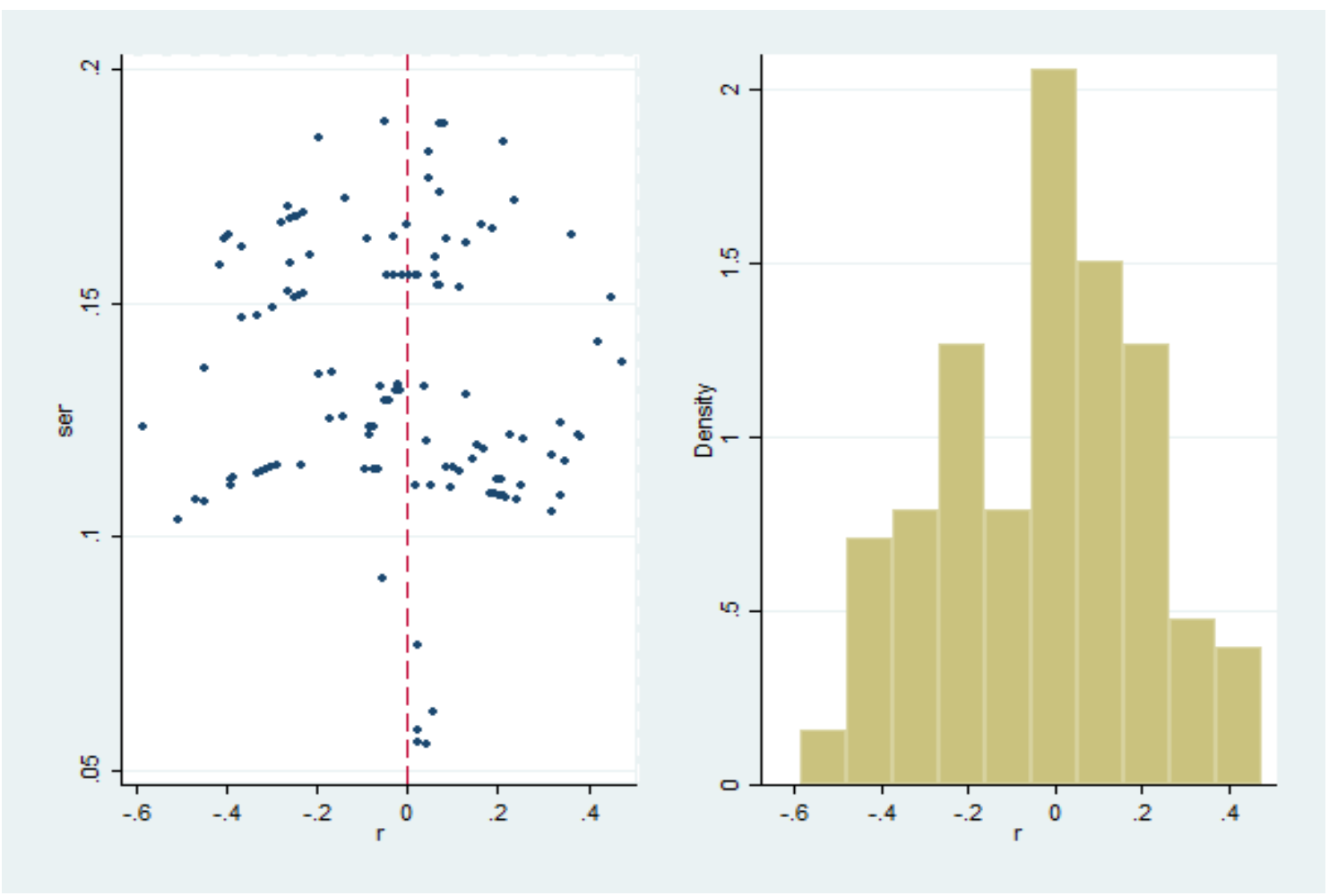

Notes: Figure (a) depicts the scatter plot of the partial correlations, r, and the corresponding standard errors, ser, for Trade Openness. Figure (b) shows the corresponding histogram of the reported t-statistics. 
Appendix 
Table A1: Countries included in the study

\begin{tabular}{|c|c|c|c|c|c|}
\hline Country & Disinflation episode & Sacrifice ratio & Country & Disinflation episode & Sacrifice ratio \\
\hline Argentina & $1976 \mathrm{q} 2-1977 \mathrm{q} 4$ & 0 & Indonesia & 1974q1-1978q2 & 0.6 \\
\hline Argentina & $1984 q 3-1986 q 4$ & 0.1 & Indonesia & $1980 q 2-1982 q 4$ & -1.8 \\
\hline Argentina & $1989 q 2-1997 q 1$ & 0.2 & Indonesia & $1983 q 4-1986 q 2$ & -0.9 \\
\hline Argentina & $1997 q 3-2000 q 1$ & -4.2 & Indonesia & $1998 \mathrm{q} 3-2000 \mathrm{q} 4$ & 0.6 \\
\hline Argentina & 2003q1-2004q1 & -0.1 & Indonesia & $2001 q 4-2004 q 3$ & 0.5 \\
\hline Argentina & $2006 q 1-2008 q 4$ & 3.1 & Indonesia & $2005 q 3-2010 q 4$ & 0.7 \\
\hline Argentina & $2011 q 1-2012 q 2$ & -5.2 & Ireland & $1981 q 2-1988 q 1$ & 3.0 \\
\hline Australia & $1975 \mathrm{q} 1-1979 \mathrm{q} 1$ & -0.8 & Ireland & $2001 q 2-2005 q 1$ & 3.9 \\
\hline Australia & 1982q3-1985q1 & 6.8 & Ireland & $2007 q 3-2010 q 2$ & 1.1 \\
\hline Australia & $1989 q 2-1993 q 2$ & 2.5 & Israel & $1974 q 4-1976 q 4$ & -1.5 \\
\hline Australia & 1995q3-1998q3 & 0.5 & Israel & $1984 q 4-1988 q 3$ & 0.1 \\
\hline Austria & $1974 q 4-1979 q 1$ & 5.3 & Israel & 1990q1-1993q4 & -1.0 \\
\hline Austria & $1981 \mathrm{q} 2-1987 \mathrm{q} 3$ & -0.7 & Israel & 1994q1-2001q1 & -15.5 \\
\hline Austria & 1993q1-1998q4 & 6.2 & Israel & $2002 q 2-2004 q 3$ & 3.2 \\
\hline Belgium & $1975 q 2-1979 q 2$ & -0.1 & Italy & $1975 q 4-1978 q 4$ & -2.1 \\
\hline Belgium & $1982 q 3-1987 q 4$ & 5.9 & Italy & $1980 q 4-1988 q 1$ & 5.6 \\
\hline Belgium & 1990q3-1999q1 & 29.1 & Italy & $1990 q 2-1994 q 2$ & 4.1 \\
\hline Brazil & $1985 q 2-1986 q 3$ & -0.1 & Italy & $1995 q 2-1998 q 4$ & 0.0 \\
\hline Brazil & $1989 q 4-1992 q 2$ & 0.0 & Japan & $1980 q 4-1987 q 4$ & 5.4 \\
\hline Brazil & $1993 q 4-1998 q 4$ & 0.0 & Japan & $1980 q 4-1987 q 4$ & 5.4 \\
\hline Brazil & $2002 q 4-2007 q 2$ & 5.1 & Japan & $1990 q 4-1995 q 4$ & 4.9 \\
\hline Canada & $1975 q 1-1977 q 3$ & 1.2 & Korea & $1975 q 1-1977 q 4$ & 0.0 \\
\hline Canada & $1981 q 3-1985 q 4$ & 8.7 & Korea & $1980 q 3-1984 q 4$ & 1.2 \\
\hline Canada & $1990 q 3-1994 q 2$ & 13.2 & Korea & 1991q1-1996q4 & -0.5 \\
\hline Chile & $1974 q 4-1982 q 2$ & -1.0 & Korea & $1997 q 4-2000 q 2$ & 14.7 \\
\hline Chile & $1984 q 3-1988 q 4$ & 20.7 & Latvia & $2008 \mathrm{q} 1-2010 \mathrm{q} 4$ & 6.2 \\
\hline Chile & 1990q3-2004q4 & -24.6 & Luxembourg & $1975 q 3-1979 q 1$ & 1.1 \\
\hline Chile & 2008q1-2010q3 & 5.1 & Luxembourg & $1982 q 3-1987 q 3$ & 3.9 \\
\hline China & $1988 \mathrm{q} 3-1991 \mathrm{q} 2$ & -1.8 & Luxembourg & $1992 q 3-1998 q 4$ & 36.7 \\
\hline China & $1994 q 3-1999 q 2$ & -11.8 & Mexico & $1974 q 3-1975 q 4$ & -0.5 \\
\hline China & $1994 q 3-1999 q 2$ & -11.8 & Mexico & $1977 q 4-1979 q 2$ & -0.1 \\
\hline Colombia & $1974 q 3-1975 q 4$ & 0.3 & Mexico & $1983 q 3-1985 q 2$ & -0.3 \\
\hline Colombia & $1977 q 1-1979 q 2$ & -3.3 & Mexico & 1987q3-1994q1 & 0.2 \\
\hline Colombia & $1980 q 4-1984 q 2$ & -10.0 & Mexico & $1996 q 2-2007 q 1$ & -3.2 \\
\hline Colombia & $1991 q 2-2006 q 2$ & 50.3 & Netherlands & $1981 q 2-1987 q 3$ & 8.9 \\
\hline Colombia & 2008q1-2010q4 & 7.0 & Netherlands & $2001 q 4-2006 q 1$ & 17.2 \\
\hline Czechia & $1992 \mathrm{q} 4-1996 \mathrm{q} 4$ & 0.5 & New Zealand & $1980 q 4-1984 q 2$ & 0.3 \\
\hline Czechia & $1997 q 3-2000 q 2$ & 4.2 & New Zealand & $1984 q 2-1993 q 1$ & 4.8 \\
\hline Czechia & 2001q1-2003q3 & 2.6 & New Zealand & 1995q4-1999q1 & 1.1 \\
\hline Czechia & 2008q1-2010q3 & 5.3 & Norway & $1975 q 3-1979 q 2$ & -2.1 \\
\hline Denmark & $1974 q 3-1976 q 4$ & 3.7 & Norway & $1981 q 3-1985 q 3$ & 8.6 \\
\hline Denmark & 1980q4-1987q1 & 0.1 & Norway & 1987q3-1994q1 & 15.5 \\
\hline Denmark & 1988q4-1994q1 & 7.4 & Portugal & $1977 q 4-1980 q 4$ & -0.4 \\
\hline Estonia & $2001 q 2-2003 q 4$ & 0.2 & Portugal & $1984 q 2-1988 q 1$ & 2.6 \\
\hline Estonia & $2007 q 4-2010 q 2$ & 9.0 & Portugal & $1990 q 2-1999 q 2$ & 7.3 \\
\hline Finland & $1975 q 1-1979 q 2$ & 6.2 & Portugal & 2007q1-2010q1 & -2.7 \\
\hline Finland & $1981 q 2-1987 q 1$ & -0.1 & Russia & $1999 \mathrm{q} 3-2007 \mathrm{q} 1$ & 0.6 \\
\hline Finland & $1989 q 4-1996 q 3$ & 35.8 & Slovakia & $1994 q 1-1997 q 2$ & -0.7 \\
\hline Finland & 2001q1-2005q1 & 7.2 & Slovakia & $2000 q 3-2002 q 2$ & 0.9 \\
\hline Finland & $2007 q 4-2010 q 2$ & 8.5 & Slovakia & $2003 q 4-2006 q 4$ & 4.8 \\
\hline France & $1975 q 1-1978 q 1$ & 2.6 & Slovakia & $2007 q 3-2010 q 2$ & -7.9 \\
\hline France & $1981 q 2-1987 q 3$ & 2.3 & Slovenia & 2001q1-2006q2 & 7.7 \\
\hline Germany & $1981 \mathrm{q} 1-1987 \mathrm{q} 2$ & 6.4 & Slovenia & $2007 q 4-2010 q 3$ & 3.1 \\
\hline Germany & $1992 q 3-1996 q 3$ & 3.6 & South Africa & 1981q4-1984q1 & 7.7 \\
\hline Greece & $1974 q 4-1978 q 1$ & -8.1 & South Africa & $1986 q 2-1989 q 2$ & -0.6 \\
\hline Greece & $1980 q 4-1984 q 4$ & -2.5 & South Africa & $1991 q 3-1997 q 3$ & 8.4 \\
\hline Greece & $1985 q 4-1989 q 1$ & 3.3 & South Africa & $1997 q 4-2000 q 4$ & 6.0 \\
\hline Greece & 1991q1-2000q2 & 11.2 & South Africa & $2002 q 2-2005 q 1$ & 1.4 \\
\hline Hungary & 1991q1-1994q2 & 0.5 & South Africa & 2008q3-2011q1 & 5.4 \\
\hline Hungary & $1995 q 4-2003 q 2$ & 3.1 & Spain & $1977 q 2-1988 q 2$ & 12.3 \\
\hline Iceland & $1980 q 4-1981 q 4$ & -0.2 & Spain & $1990 \mathrm{q} 1-1998 \mathrm{q} 3$ & 12.8 \\
\hline Iceland & 1983q1-1987q3 & 1.2 & Spain & 2007q3-2010q1 & -3.9 \\
\hline Iceland & $1988 \mathrm{q} 4-1995 \mathrm{q} 3$ & 2.3 & Sweden & $1977 q 2-1979 q 1$ & 2.3 \\
\hline Iceland & $2001 q 2-2003 q 4$ & -0.3 & Sweden & $1980 q 4-1987 q 2$ & 9.2 \\
\hline Iceland & 2009q1-2012q1 & 9.7 & Sweden & 1990q4-1998q1 & 13.2 \\
\hline India & $1974 q 2-1976 q 4$ & 0.0 & Sweden & 2007q4-2010q1 & 10.1 \\
\hline India & 1981q1-1985q3 & -0.7 & Switzerland & $1974 q 2-1978 q 1$ & 8.3 \\
\hline India & 1991q3-1994q1 & 2.0 & Switzerland & 1982q1-1987q2 & 9.4 \\
\hline India & $1997 q 3-2000 q 4$ & -2.0 & Switzerland & 1991q1-1998q3 & 12.9 \\
\hline India & $2009 q 4-2012 q 1$ & -8.5 & Turkey & $1974 q 3-1976 q 3$ & 0.0 \\
\hline
\end{tabular}




\begin{tabular}{cccccc}
\multicolumn{7}{c}{ Table 10 - continued from previous page } & & & \\
\hline Country & Disinflation episode & Sacrifice ratio & Country & Disinflation episode & Sacrifice ratio \\
\hline Turkey & $1979 \mathrm{q} 4-1982 \mathrm{q} 4$ & 0.7 & UK & $1980 \mathrm{q} 3-1984 \mathrm{q} 2$ & 3.2 \\
Turkey & $1985 \mathrm{q} 1-1986 \mathrm{q} 4$ & 1.3 & UK & $1991 \mathrm{q} 1-2001 \mathrm{q} 1$ & 15.1 \\
Turkey & $1989 \mathrm{q} 2-1990 \mathrm{q} 2$ & 0.9 & $\mathrm{US}$ & $1974 \mathrm{q} 4-1977 \mathrm{q} 2$ & 4.7 \\
Turkey & $1995 \mathrm{q} 2-1996 \mathrm{q} 3$ & -0.1 & $\mathrm{US}$ & $1980 \mathrm{q} 3-1984 \mathrm{q} 2$ & 4.6 \\
Turkey & $1997 \mathrm{q} 3-2005 \mathrm{q} 2$ & 3.0 & US & $1990 \mathrm{q} 2-1995 \mathrm{q} 1$ & 14.1 \\
Turkey & $2007 \mathrm{q} 4-2010 \mathrm{q} 3$ & 21.0 & US & $2007 \mathrm{q} 3-2010 \mathrm{q} 1$ & 3.1 \\
UK & $1975 \mathrm{q} 2-1978 \mathrm{q} 4$ & 3.4 & & & \\
\hline \hline
\end{tabular}

Notes: Sacrifice ratios calculated using the methodology proposed by Ball (1994).

Table A2: Body/agency that supervises banks for prudential purposes

\begin{tabular}{cc}
\hline $\begin{array}{c}\text { Central bank or single/multiple } \\
\text { bank supervisory agencies } \\
\text { (including central bank) }\end{array}$ & $\begin{array}{c}\text { Single or multiple bank } \\
\text { supervisory agencies } \\
\text { (different from central bank) }\end{array}$ \\
\hline Argentina & Australia \\
Austria & Canada \\
Belgium & Chile \\
Brazil & China \\
Czechia & Colombia \\
Estonia & Denmark \\
Finland & Indonesia \\
France & Japan \\
Germany & Korea \\
Greece & Mexico \\
Hungary & Norway \\
Iceland & Sweden \\
India & Switzerland \\
Ireland & Turkey \\
Israel & \\
Italy & \\
Latvia & \\
Luxembourg & \\
Netherlands & \\
New Zealand & \\
Portugal & \\
Russia & \\
Singapore & \\
Slovenia & \\
Spain & \\
UK & \\
US & \\
& \\
\hline
\end{tabular}

Notes: Source: The World Bank, Bank Regulation and Supervision Survey, 2019. Question 12.1. Values as of end 2016. 
Table A3: Alternative hyper-g priors with fixed values for $a$ parameter

\begin{tabular}{cccccccc}
\hline Variable & $\mathrm{PIP}_{A}$ & $\mathrm{PIP}_{B}$ & $\mathrm{PIP}_{C}$ & $\mathrm{PIP}_{D}$ & $\mathrm{PIP}_{E}$ & $\mathrm{PIP}_{F}$ & Effect on SR \\
\hline Peak & 0.287 & 0.296 & 0.305 & 0.468 & 0.492 & 0.513 & + \\
$\Delta \pi$ & 0.286 & 0.296 & 0.305 & 0.468 & 0.491 & 0.512 & - \\
Length & $0.812^{c}$ & $0.811^{c}$ & $0.810^{c}$ & $0.831^{c}$ & $0.844^{c}$ & $0.853^{c}$ & + \\
Speed & $0.829^{c}$ & $0.829^{c}$ & $0.827^{c}$ & $0.843^{c}$ & $0.856^{c}$ & $0.864^{c}$ & - \\
Separation & 0.294 & 0.303 & 0.312 & 0.472 & 0.496 & 0.516 & + \\
IT & 0.412 & 0.420 & 0.427 & 0.563 & 0.585 & 0.603 & + \\
CBI & $0.857^{c}$ & $0.856^{c}$ & $0.855^{c}$ & $0.876^{c}$ & $0.885^{c}$ & $0.891^{c}$ & - \\
TO & 0.499 & 0.506 & 0.512 & 0.628 & 0.648 & 0.664 & + \\
Debt & 0.520 & 0.526 & 0.531 & 0.642 & 0.662 & 0.678 & + \\
EXR & 0.292 & 0.302 & 0.311 & 0.470 & 0.494 & 0.515 & - \\
FD & 0.367 & 0.376 & 0.385 & 0.526 & 0.549 & 0.567 & + \\
CO & $0.992^{a}$ & $0.991^{a}$ & $0.990^{a}$ & $0.994^{a}$ & $0.993^{a}$ & $0.992^{a}$ & + \\
\hline
\end{tabular}

Notes: PIP stands for posterior inclusion probability. Subscripts A, B and C indicate the hyper-g prior with $a$ having a fixed value of 2.5, 3 and 3.5, respectively with uniform used as model prior. Subscripts D, $\mathrm{E}$ and $\mathrm{F}$ indicate the hyper-g prior with $a$ having a fixed value of $2.5,3$ and 3.5 , respectively with beta-binomial used as model prior. $a / b / c$ denotes decisive/strong/positive evidence of a regressor having an effect, respectively, according to Kass and Raftery (1995). +/- shows the estimated sign of the posterior mean of the corresponding coefficient.

Table A4: Summary of the estimated specifications

\begin{tabular}{ccccc}
\hline Case & Parameter prior & Model prior & Results in & Purpose \\
\hline i & Hyper-g & Uniform & Table 3 & Testing different model priors \\
ii & Hyper-g & Beta-binomial & Table 3 & Testing different model priors \\
iii & Hyper-g with fixed $a$ & Uniform & Table A3 & Testing the robustness of fixed $a$ \\
iv & Hyper-g with fixed $a$ & Beta-binomial & Table A3 & Testing the robustness of fixed $a$ \\
v & Empirical Bayes g & Uniform & Table 4 & Testing different parameter prior \\
vi & UIP & Uniform & Table 4 & Testing different parameter prior \\
vii & UIP & Uniform & Table 5 & Fixed effects \\
viii & UIP & Uniform $(\theta<0.5, \theta>0.5)$ & Table 6 & Fixed effects \& testing model prior \\
ix & Repeat i,ii,v,vi & Repeat i,ii,v,vi & Table 7 & Removing outliers \\
x & Repeat vii,viii & Repeat vii,viii & Table 8 & Removing outliers \\
xi & Repeat i,ii,v,vi & Repeat i,ii,v,vi & Table 9 & Removing outliers \& country grouping \\
\hline
\end{tabular}

